\title{
REVISTAACIÓN
}

Revista Educación

ISSN: 0379-7082

ISSN: 2215-2644

revedu@gmail.com

Universidad de Costa Rica

Costa Rica

\section{Dimensión pedagógica de los lugares de memoria: semiosis nemotécnica, visita presencial y extensión virtual}

Cuesta Moreno, Oscar Julián; Lara Salcedo, Luz Marina; Mora Hernández, Yaneth; Burgos Urán, Félix Andrés; Sánchez Guerra, Laura; Marín, Adriana María

Dimensión pedagógica de los lugares de memoria: semiosis nemotécnica, visita presencial y extensión virtual Revista Educación, vol. 46, núm. 1, 2022

Universidad de Costa Rica, Costa Rica

Disponible en: https://www.redalyc.org/articulo.oa?id=44068165009

DOI: https://doi.org/10.15517/revedu.v46i1.44708

\section{(c) (1) $\Theta(9$}

Esta obra está bajo una Licencia Creative Commons Atribución-NoComercial-SinDerivar 3.0 Internacional. 


\section{Dimensión pedagógica de los lugares de memoria: semiosis nemotécnica, visita presencial y extensión virtual}

Pedagogical Aspects of Memory Sites: Mnemonic Semiosis, On-Site Visits and Virtual Extension

Oscar Julián Cuesta Moreno

Pontificia Universidad Javeriana, Colombia

ocuesta@javeriana.edu.co

(D) https://orcid.org/0000-0001-7181-1183

Luz Marina Lara Salcedo

Pontificia Universidad Javeriana, Colombia

laral@javeriana.edu.co

(iD https://orcid.org//0000-0003-0182-6878

Yaneth Mora Hernández

Investigadora independiente, Colombia

yanethmorah@gmail.com

(iD https://orcid.org/0000-0002-0969-5422

Félix Andrés Burgos Urán

Indiana University East, Estados Unidos

fburgos@iu.edu

(iD https://orcid.org/0000-0003-4631-1675

Laura Sánchez Guerra

Museo casa de la Memoria, Colombia

laura.sanchez@museocasadelamemoria.gov.co

(iD) https://orcid.org/0000-0001-7639-1966

Adriana María Marín

Museo casa de la Memoria, Colombia

adriana.marin@museocasadelamemoria.gov.co

(iD) https://orcid.org/0000-0002-3778-6276
DOI: https://doi.org/10.15517/revedu.v46i1.44708 Redalyc: https://www.redalyc.org/articulo.oa? $\mathrm{id}=44068165009$
Recepción: 05 Diciembre 2020

Aprobación: 12 Febrero 2021

\section{Resumen:}

El artículo sostiene que los lugares de memoria poseen una dimensión pedagógica constitutiva, caracterizada por la contingencia comunicativa que no permite reducir la interpretación del pasado a una sola versión. Para ello, se propone el concepto de semiosis nemotécnica. Además, el texto reflexiona sobre las características de los lugares de memoria y su vínculo con el patrimonio; argumenta que esto es necesario para lograr la reparación de las víctimas y la participación activa de la comunidad en su territorio. En ese marco, se muestran los retos de extender estos lugares a escenarios virtuales. Finalmente, se describe la experiencia del Museo Casa de la Memoria de Medellín como ejemplo de los argumentos expuestos en el artículo.

Palabras Clave: Lugares de memoria, Memoria, Pedagogía, Conflicto armado, Semiosis nemotécnica.

\section{Abstract:}


Memory sites have a built-in pedagogical dimension described as communication shortcomings which prevent past events from prevented from being interpreted as a one, single version. This study uses mnemonic semiosis associated to armed conflict to reflect on the characteristics of memory sites and how they are linked to a deeper cultural perspective where active community participation is necessary for victim reparations. Within this context, the challenges of extending memory sites to virtual scenarios is also addressed using the experience of the Museo Casa de la Memoria Museum in the city of Medellin, Colombia as an example of the arguments presented herein.

KeYwords: Memory Sites, Memory, Pedagogy, Armed Conflict Mnemonic Semiosis.

\section{INTRODUCCIÓN}

Para Jelin (2002), la memoria es un proceso colectivo que lleva a pensar no en una memoria, sino en memorias, en plural. Este conjunto de memorias no ocurre individualmente, sino que se genera en grupos, instituciones y culturas. Las memorias individuales están siempre en el marco social, pues quienes tienen memoria y recuerdan son seres humanos ubicados en contextos sociales específicos.

Ahora bien, el pasado tiene sentido a partir del acto presente de rememorar y olvidar. La rememoración implica una experiencia pasada que se moviliza en el presente y que se puede comunicar. Sin embargo, este proceso está mediado por una selección no siempre inocente. Toda narrativa del pasado implica una elección de recuerdos, así como de silencios y olvidos realizados por actantes sociales que tienen intereses particulares en lo que respecta a la recuperación de la memoria. Es en este contexto que las luchas por la memoria se configuran al generar una confrontación por las representaciones del pasado, que tienen como eje central las luchas por el poder y la legitimidad, y el reconocimiento.

La activación de las memorias a menudo provoca tensiones y conflictos, se convierte en un campo de luchas ideológicas que se han materializado en lugares de memoria, los cuales, tal como lo señala Nora (2009), abarcan fechas, aniversarios, conmemoraciones, monumentos y, en general, diferentes espacios físicos.

Precisamente, este artículo reflexiona[1] sobre los lugares de memoria en Colombia, sus características y vínculos con el patrimonio. Además, sostiene que estos lugares tienen una dimensión pedagógica constitutiva que se basa en la semiosis nemotécnica, que permite una contingencia reflexiva que deviene de un acontecimiento ético de hacerse responsable de las partes ausentes. Asimismo, se plantean unas consideraciones de los lugares de memoria extendidos a plataformas virtuales. Finalmente, se analizan los vínculos entre los lugares de memoria, el territorio y la participación comunitaria, para lo cual se toma por caso el Museo de Memoria en Medellín.

\section{ELEMENTOS CONSTITUTIVOS DE LOS LUGARES DE MEMORIA}

Nora (2001) definió a los lugares de memoria, en general, como aquellos espacios donde se cimenta, densifica, guarda y comunica la memoria colectiva. Sin embargo, no solo los espacios hacen parte de este grupo de lugares, también las construcciones simbólicas y materiales, como conmemoraciones, fiestas y narraciones.

Ahora bien, no es cualquier lugar el que se recuerda, sino aquel donde la memoria actúa. Entonces, los lugares de la memoria, como espacialización del recuerdo, son territorio del acontecimiento, toda vez que el hecho a recordar haya sucedido en ese lugar o esté vinculado a este. En consecuencia, los lugares de no están seleccionados arbitrariamente, puesto que poseen un vínculo histórico, social y topográfico que les da sentido.

Ahora bien, un lugar de acontecimiento es un lugar de memoria para quienes estuvieron allí como testigos; pero para las demás personas es un lugar de formación, ya que en él pueden ampliar saberes y alcanzar conocimientos asociados a emociones que permitan la construcción del recuerdo. Luego, quien visita un lugar de memoria tiene la posibilidad de aprender.

Por otro lado, advierte Allier (2008), el lugar de memoria tiene una condición de encrucijada, ya que se encuentran diversas rutas de la memoria, "como su capacidad para perdurar y ser incesantemente remodelado, 
re-abordado y revisitado" (p. 167). Asimismo, el lugar de memoria no está dado, es construido y reconstruido. Además, tienen una inmanencia temporal contemporánea, con horizonte epistemológico en la actualidad, es decir, "la evaluación del pasado en el presente" (Allier, 2008, p. 180) a través de los significados atribuidos desde la perspectiva de la historia presente.

En ese marco, en escenarios de posconflicto y construcción de paz como Colombia, los lugares de memoria llevan a la discusión pública los hechos de violencia acaecidos y contribuyen a transformar las relaciones sociales y la estigmatización que impusieron los grupos armados sobre parte de la población, para lograr así una cultura de paz. De esta manera, los lugares de memoria territorializan la voz de las víctimas y sus proyectos de resistencia, pues contribuyen, en su reconocimiento, a la difusión de la verdad y la preservación de la memoria; su principal objetivo es sensibilizar a la sociedad y avanzar en el restablecimiento de los derechos de las víctimas.

\section{EL FLORECIMIENTO DE LOS LUGARES DE MEMORIA}

Se podría decir que hay una explosión de la memoria. Esto se debe a varios factores. Primero, los lugares de memoria están enmarcados dentro de una tendencia mundial de creación de lugares que actúan como Sitios de Conciencia, es decir, son espacios de memoria que realizan acciones intencionadas, tanto para recordar el pasado, como para abrir el diálogo público sobre los legados contemporáneos que aún resultan conflictivos. Segundo, los múltiples propósitos vinculados con los lugares de memoria han beneficiado su auge. Además, a esto se suma la dimensión emocional del recuerdo de las víctimas, que es crucial para sobrevivientes y familiares. Es relevante, también, la dimensión cognitiva o informativa del pasado transmitido a la sociedad, $\mathrm{y}$, sobre todo, a las siguientes generaciones.

En tercer lugar, cómo tratar ese pasado difícil también ha despertado un gran interés por la globalización de los lenguajes de la memoria: formas estéticas, presentaciones, monumentos, memoriales diseñados pedagógicamente, instalaciones artísticas y memorias en movimiento (Birle et al., 2010), y también, desde la investigación sensible para descubrir esos otros lenguajes de la memoria inscritos en la experiencia sensible, que se manifiesta en los olores, colores, sabores y texturas de la memoria.

Cuarto, porque son producto de los debates y de la confrontación pública con el pasado de las y los participantes sociales en la lucha permanente por los Derechos Humanos y por la preponderancia de asignación de sentido a espacios que antes tenían otros usos o significados, que ahora, gracias a políticas públicas de la memoria asociadas a demandas ciudadanas, adquieren nuevos sentidos a partir de su consumación.

En Colombia, los lugares de memoria del conflicto armado y la violencia sociopolítica son una medida de satisfacción, en el marco de la reparación simbólica que consagra la Ley 1448 de 2011 (Congreso de la República de Colombia, 2011). Además, la creación de estos lugares busca establecer escenarios de conmemoración, reparación, visibilización y denuncia de los hechos ocurridos en el marco del conflicto armado y la violencia sociopolítica generada.

\section{Vínculos entre Patrimonio y Lugares de Memoria}

El florecimiento de los lugares de memoria también se debe a la importancia del concepto de patrimonio de la nueva museología (Mora, 2013). De allí que se pueda hablar del vínculo entre patrimonio y lugares de memoria, puesto que patrimonio remite a los bienes y manifestaciones que hacen parte del legado cultural que se transmite de generación en generación. A través de esta herencia se fortalece la memoria de una comunidad, así como su identidad. 
Los bienes considerados patrimoniales no fueron necesariamente concebidos como tales, sino que han sido los grupos humanos que los han heredado quienes les han dado valor y los han transmitido a las generaciones venideras (Fontal, 2013). Esta concepción reconoce el patrimonio como propiedad de las comunidades en donde su preservación y autogestión plantean un nuevo paradigma que supera la visión tradicional: de algo que pertenecía a las elites de las sociedades, a algo heredado por todas las personas y que por tanto es propiedad de todos y todas; allí radica el concepto de apropiación social del patrimonio.

Ahora bien, el patrimonio cultural es producto de la activación de la memoria, que selecciona elementos heredados del pasado, con los que construye procesos de interacción social con el presente y el futuro. La memoria es el soporte de las identidades: sin memoria no habría identidad, de allí que la memoria no se puede entender sin hacer referencia a las identidades en todas sus formas y expresiones, y del mismo modo, las identidades no funcionan sin la memoria colectiva.

En este contexto, nuevas expresiones y lugares de memoria, relacionadas mayormente con el relato de las víctimas, artistas y colectivos culturales, han hecho su aparición en el marco de estas luchas por la memoria, las cuales se han tramitado y expresado a través del patrimonio cultural. A partir de sus múltiples manifestaciones se han discutido y confrontado hechos traumáticos, como denuncia ante el silencio y la impunidad, o la forma de exigir -directa o indirectamente del Estado y de la sociedad- condiciones de igualdad y trato digno (Sierra, 2017).

El patrimonio cultural, material o inmaterial, se ha convertido en un mecanismo para exaltar y denunciar, ante la sociedad, situaciones traumáticas producidas por el accionar de actantes armados oficiales o no oficiales en ciertas comunidades del país. Estas denuncias se han manifestado a través de diferentes expresiones orales, tejidos, presentaciones, cantos, obras de teatro, lugares y memoriales que han permitido resignificar acciones de resistencia y dignidad.

Muchas de estas comunidades son marginales, ajenas a la institucionalidad central y a la presencia real del Estado. La forma en cómo tratan de solventar estas carencias es a través de tradiciones autóctonas colectivas que hablan de sus luchas sociales permanentes. Estas manifestaciones nacen del seno de la comunidad, se fortalecen y se divulgan por quienes comparten una realidad cultural y desean construir memorias locales a partir de una puesta en escena que dialoga con el pasado traumático y el presente por construir. Para estas comunidades, la práctica cultural se convierte en un medio para la demanda y reivindicación de derechos, así como para la reconstrucción de los vínculos sociales solidarios y comunitarios rotos por el conflicto armado.

\section{LOS LUGARES DE MEMORIA COMO UN MECANISMO DE REPARACIÓN SIMBÓLICA}

Para que un lugar de memoria pueda contribuir con la reparación de las comunidades y de las víctimas, es necesario que cuente con una intencionalidad de memoria clara. Esto implica identificar y dar respuesta a las necesidades de memoria específicas que las víctimas, las organizaciones y las comunidades tienen en el presente, según su propia historia y contexto.

Desde el marco normativo internacional en materia de verdad, justicia y reparación integral (Sistema Nacional de Atención y Reparación Integral a las Víctimas [SNARIV], 2015), se resaltan varios derechos para las víctimas. En primer lugar, el derecho a la verdad que tienen para construir memoria histórica y enfrentar o hacerse cargo del pasado. En este sentido, la creación y el reconocimiento de lugares de memoria resultan medidas adecuadas para reconstruir los hechos ocurridos, darlos a conocer y contribuir en materializar el derecho a la verdad, por lo cual los relatos y las narrativas de estos lugares de memoria se convierten en el medio para que la sociedad conozca lo ocurrido. En segundo lugar, el derecho a la memoria colectiva reconoce los lugares de memoria como soporte de la memoria colectiva, puesto que pueden contribuir a esclarecer lo ocurrido, respaldar las denuncias y los relatos individuales, y a tramitar mejor las situaciones traumáticas del pasado; así aportan a la construcción y transmisión de memorias colectivas. 
En tercer lugar, el derecho a la reparación busca que las víctimas superen tal condición a través del acceso efectivo a sus derechos, y su reconocimiento pleno como parte de la ciudadanía. Como medida de reparación simbólica, los lugares de memoria constituyen una forma de satisfacción para las víctimas.

\section{La dimensión pedagógica de los lugares de memoria y semiosis nemotécnica}

Los lugares de memoria tienen una naturaleza que interpela, ya que requiere una respuesta de su visitante. Si bien su interpelación no es necesariamente una pregunta explícita, sí produce resonancias que exigen alguna explicación. Dado que la memoria nunca está totalmente osificada al ser un asunto político, colectivo y, sobre todo, subjetivo, las preguntas se actualizan y se desprenden nuevas explicaciones.

Los lugares de memoria tienen gran capacidad de interpelar porque son, en esencia, escenarios de enunciación: su materialidad está revestida por múltiples símbolos que evocan diversos significados, muchos de ellos no fijados, sino abiertos a la comprensión de quien lo visita.

De hecho, "un mensaje que significa una cosa para sus autores/as y gestores/as, puede significar otra totalmente distinta para quienes lo visitan, y ese significado cambia según la experiencia de los/las visitantes" (Montenegro et al., 2015, p. 1725).

En ese orden, los lugares de memoria tienen una constitución enunciativa que se caracteriza por su dinámica de tensión: lo que se expresa y lo que se interpreta está abierto a la contingencia. De allí que su interpelación sea profundamente subjetiva: la persona visitante no asiste a una exposición cuyo significado está programado, sino que se ve inmersa a una dinámica que le exige su participación, puesto que es ella la que debe asumir de alguna manera la semiosis nemotécnica, es decir, la producción de significado que da sentido a la memoria.

Por ello, los lugares de memoria tienen gran capacidad de interpelación a sus visitantes, porque la distancia entre la materialidad del escenario y el significado que cada visitante puede producir en su interpretación está abierto. Tal contingencia permite que se fragüen efectos afectivos emocionales toda vez que la exigencia de interpretación es sobre el dolor y la muerte de la otredad. Así, la semiosis que se desencadena no opera solo en el plano intelectual, sino que se imbrica en afectaciones de alta densidad emocional: el significado que se asigna y que orienta la memoria no es de orden hierático, sino que, por el contrario, es expresamente sentimental.

Ahora bien, la tensión entre la materialidad del lugar y la interpretación que puede producir en sus visitantes es de naturaleza política y pública toda vez que la experiencia que se produce es sobre los eventos ocurridos en la dinámica social; por ello, los significados que se le asignan al pasado se vinculan a los significados que se producen y se asocian al lugar (Piper et al., 2013).

La tensión que produce la enunciación del lugar de memoria se debe, entre otras cosas, a que la materialidad y planificación del lugar de memoria (como lo puede ser un museo)

Llevan consigo una carga simbólica que contribuye a construir ciertas versiones del pasado, sin embargo, aunque en dicho escenario hay algunas versiones del pasado que son privilegiadas, la propuesta de interpretación del ensamblaje semiótico-material queda abierta a diferentes lecturas realizadas a partir de la experiencia misma de recorrer el lugar (Montenegro et al., 2015, p.1725).

En pocas palabras, si bien el lugar puede ser configurado para destacar ciertos hechos o actantes, la interpretación que hace la persona visitante no está fijada de antemano, sino que está abierta a la producción de sentido por lo que se puede plantear que es posible la semiosis nemotécnica. De allí que la interpelación que hace la disposición del lugar a quien visitante genera experiencia y afecta las fibras de su subjetividad: cada visitante debe hacerse cargo del significado, pues el lugar no transfiere la memoria de manera directa e impoluta, sino que pasa por la hermenéutica emocional y política del quien realiza la visita.

Así, la disposición y objetos del lugar de memoria hablan y desencadenan significados, pero no solo lo hace su presencia, sino también su ausencia (Montenegro et al., 2015), es decir, la interpelación que siente la persona visitante es también por dar cuenta de los objetos o narraciones que no están en el lugar, pero 
a su juicio deberían ser considerados. En ese orden, se puede decir que los lugares de memoria tienen una arquitectura emocional (Vicente, 2019), que permite efectos intrasubjetivos en sus visitantes.

Además, la interpelación emocional que se genera en un lugar de memoria es de orden temporal, ya que se experimenta el presente interpretando eventos del pasado. Por ello, son lugares que tienen gran capacidad de afectación: pueden generar una contingencia donde sea posible alterar hermenéuticas y discursos osificados en la subjetividad de sus visitantes, alterando la relación, significados y explicaciones que tienen sobre los eventos ocurridos.

Por otro lado, en los lugares y museos de memoria existen diferentes piezas comunicativas, como vídeos, carteles, audios, fotos, cuadros, monumentos, todos con una carga comunicativa, que de algún modo interpela. Muchas de estas piezas son testimonio de las víctimas ausentes o de sus madres, padres, hijos, hijas, cónyuges y colegas, que dan cuenta de su ausencia. Así, los lugares interpelan porque en ellos hay una contingencia comunicativa, es decir, de mucha información que no se reduce a un solo mensaje y cuya interpretación no se puede reducir o controlar.

Todos los testimonios son más que necesarios para la construcción de la memoria. Sin embargo, los lugares de memoria tienen una gran capacidad para interpelar desde el silencio: la no-palabra de las partes ausentes que no puede ser reemplazada por el testimonio de otras personas. En ese orden, son lugares que tienen la posibilidad de resguardar el silencio y, así, que sus visitantes puedan sentirlo. Este no es cualquier silencio, es el de quienes están ausentes, de las víctimas que no pueden decir lo que pasó. Ese silencio tiene una gran carga comunicativa e interpela directamente a la persona visitante: su ausencia sepulcral la acompaña y le inquiere una respuesta: o el silencio pasa cínicamente en el retumbe del olvido o el silencio se acoge éticamente a la no-presencia de la otredad y desencadena la posibilidad de la semiosis nemotécnica que asigna significado al pasado y sentido al futuro.

Si bien se le puede señalar al silencio su impresión o ambigüedad, precisamente esta cualidad es la que le brinda su capacidad interpelativa: provoca tal vez más preguntas que respuestas: los hechos ocurridos, el dolor y la ausencia gélida de la otredad no puede ser agotada con palabras y la experiencia que brinda el lugar puede ser inefable, por lo que afecta a la persona visitante que se deja interpelar. Se presenta la oportunidad de construir una memoria del pasado abierta en su hermenéutica e inacabada en su consecución, pues no se puede llenar con interpretaciones el silencio de las partes ausentes, dado que no se puede hablar totalmente por ellas, así que siempre existirá un vacío, una imprecisión, una incertidumbre, que es ética y políticamente potencial, porque permite que la memoria se tensione y no se sedimente.

Ahora bien, el hecho de que los lugares de memoria generan impresiones emocionales y afectivas, no lleva a sus visitantes a comprender automáticamente qué circunstancias sociales, políticas y económicas hicieron posible lo ocurrido. Desde luego, tales experiencias emocionales no derivan mecánicamente en un compromiso por 'nunca más' y la no repetición de tales hechos (Droguett et al., 2018); de allí que sea necesario un momento de reflexión sobre la experiencia que desencadena la visita. Por ello, es pertinente pensar los lugares de memoria como escenarios pedagógicos.

Al tener presente que los lugares de memoria interpelan a sus visitantes, pero que dicha interpelación no puede controlarse de manera algorítmica puesto que está abierta a dinámicas de interpretación no ajenas a la tensión, pensar en estos lugares como escenarios pedagógicos no pasa por determinar la experiencia que en ellos se puede vivir, sino que, por el contrario, se trata de garantizar su apertura hermenéutica y subjetiva.

En efecto, la pedagogía tiene por orden teleológico establecer qué sociedad se desea alcanzar y qué sujeto se necesita formar para lograr dicha sociedad. Para ello, la pedagogía se establece como un campo que reflexiona, investiga, conceptualiza, teoriza sobre la educación y, de fondo, piensa qué y para qué educar. Estas preguntas no tienen respuestas absolutas, por el contrario, son históricas, es decir, están abiertas al debate.

Esta cualidad de la pedagogía de estar impulsada por preguntas siempre abiertas es lo que permite, precisamente, organizar los lugares de memoria sin parámetros condicionantes o fijados a una versión de la historia. Así, la pedagogía es siempre un llamado a pensar en la sociedad deseada y las personas que deben 
ser formadas para alcanzarla. Se trata de reconocer en los lugares de memoria la posibilidad de disponer el espacio para generar una interpelación en cada sujeto, que le lleve a pensar sobre el futuro de la sociedad desde la interpretación del pasado, de tal modo que la reflexión pedagógica sea resultado de la propia experiencia de las personas visitantes y no una reflexión orientada por presupuestos arbitrarios.

Así, lo que puede convertir a los lugares de memoria en escenarios pedagógicos no es una disposición u orden que garantice una interpretación o significación de los eventos, es decir, la fijación de una única narración o versión de lo ocurrido, pues no se trata de contar una historia oficial, sino de movilizar la subjetividad para que la persona visitante se haga cargo del pasado reciente. Desde este marco, es posible pensar, más que en una pedagogía polifónica, en una pedagogía del silencio, entendida como la posibilidad de formar personas al generar condiciones para que la subjetividad sea afectada por el silencio, básicamente escuchando y dejándose interpelar por el silencio de las partes ausentes, para que este incida formativamente en cada sujeto al experimentar el acontecimiento ético de hacerse responsable del silencio de la otredad.

La pedagogía como reflexión social hace posible pensar los lugares de memoria como espacio para la interpelación y la posibilidad de permitir una semiosis nemotécnica en sus visitantes, de tal modo que se les invite a pensar en la otredad, especialmente, en las víctimas y las partes ausentes. En efecto, son lugares para que las personas, más allá de llevarse una versión de la historia, sean invitadas a pensar qué dirían las ausentes y las víctimas de lo que les pasó, qué propondrían ellas a la sociedad desde lo que vivieron, qué sociedad quisieran tener, qué esperarían que el resto hiciera.

Esta pedagogía de los lugares y museos de la memoria evita una única versión del pasado, permite que quienes los visiten no se lleven una narración de los hechos y sus protagonistas, sino que experimenten una resonancia, una interpelación afectiva que les lleve a pensar lo ocurrido desde la ausencia de la otredad y su silencio, para así disponerse a tomar decisiones y participar en la construcción del futuro (Ruiz-Tagle y Toledo, 2009) al hacerse responsable de la interpelación que le hace la parte no-presente (Mèlich, 2001).

La pedagogía de los lugares de memoria tiene su fuerza formativa en que son escenarios que presentan la contingencia de afectar la subjetividad de sus visitantes; si se dejan interpelar, la experiencia podría llegar, en palabras de Cuesta (2018), a "problematizar los sentidos y significados que organizan su mundo" (p. 360), puesto que los lugares de memoria podrían, más allá de ratificar versiones históricas, generar preguntas. Desde luego, esto exige que las personas visitantes asistan con cierta mente abierta y disposición de dejarse interpelar, lo que implicaría una capacidad de escuchar a la otredad, incluso, a quien está ausente.

Ahora bien, el riesgo pedagógico en los lugares de memoria radica en que, tal vez, la persona que realiza una visita llegue allí con una mente osificada, que no se deje interpelar, lo que le impide tener una experiencia abierta y contingente, por el contrario, tendría un paso por el escenario que ratifica creencias, explicaciones e, incluso justificaciones, de lo ocurrido. En pocas palabras, la fuerza formativa de los lugares de memoria radica en que permiten a sus visitantes acoger a la otredad (quien está no-presente) y de esta manera mantener viva su memoria (Mèlich, 2001). Así, los lugares logran que la memoria sea, según Mèlich (2001), un “recuerdo del pasado, crítica del presente y esperanza de un futuro justo" (p. 59). Se logra que las preguntas e interpretaciones de lo ocurrido lleven al sujeto a hacerse cargo del proyecto social.

Los lugares de memoria tienen el reto de disponer su materialidad y simbolismo para lograr una empatía pedagógica, que le permitan a sus visitantes el ejercicio educativo de encontrarse con la otredad, de tal manera que logren formar sujetos que, siguiendo al Subcomandante Marcos, lleguen a decir (Ejército Zapatista de Liberación Nacional [EZLN], 2003):

yo soy como soy y tú eres como eres, construyamos un mundo donde yo pueda ser sin dejar de ser yo, donde tú puedas ser sin dejar de ser tú, y donde ni yo ni tú obliguemos al otro a ser como yo o como tú. (p.380) 


\section{EXPANSIÓN DE LOS LUGARES DE MEMORIA Y LAS PLATAFORMAS VIRTUALES}

Las discusiones y propuestas sobre la expansión de los lugares de la memoria dentro del terreno virtual han sido de particular interés en los estudios interdisciplinarios de la memoria. Para comenzar, es importante aclarar que lo virtual y lo real no son términos opuestos. De acuerdo con Farman (2012), la interacción con espacios y tecnologías digitales resulta en una práctica espacial incorpórea que no está separada de la corporalidad. Por ejemplo, existe la idea de que, al adoptar avatares o identidades virtuales, la persona separa la noción de sí misma, al alejarse de la materialidad física de su entorno. Sin embargo, la virtualidad implica una experiencia de multiplicidad entre dos contrapartes (lo virtual y lo real) que interactúan y se mantienen unidas de forma permanente (Farman, 2012). Bajo esta lógica, las propuestas virtuales de los lugares de memoria funcionan como una extensión (más que una simulación) de la experiencia corpórea de sus visitantes. Dicho de otro modo, en la virtualidad de los lugares de memoria, las visitas, recorridos, participación en foros o en actividades de realidad aumentada permiten presencia a pesar de la ausencia física de los cuerpos (Belk, 2014).

Las exhibiciones virtuales no han sido ajenas a la práctica museística. Desde mediados de los años 90, antes de la masificación del internet, diferentes tipos de exhibiciones habían sido ofrecidas al público a través de discos magnéticos o digitales (Carreras y Mancini, 2014). La incursión de estas exhibiciones en los lugares de memoria es, sin embargo, mucho más reciente debido al rápido crecimiento del internet y al desarrollo de tecnologías que permiten la navegación y acceso al mundo virtual.

De acuerdo con Silver (1997), los espacios virtuales de la memoria pueden agruparse en tres categorías generales. En la primera, el lugar de memoria, incluyendo sus colecciones y archivos, es reproducido de forma completa. Al emular el lugar de memoria se intenta darle a cada visitante la posibilidad de "ocupar" el espacio del museo de forma incorpórea. Silver denomina la segunda categoría como "el ala perdida” (p. 829), esto significa que en el espacio virtual se ofrecen documentos o experiencias adicionales a los recorridos permanentes o colecciones presentes del lugar de memoria. Dichos documentos complementan o extienden el conocimiento y la experiencia de la persona visitante. La última categoría es denominada "el sitio hiperreal” (p. 829), que busca crear un espacio y una experiencia distinta que no se encuentra dentro del espacio de la memoria. En esta categoría se encuentran aplicaciones de realidad aumentada, cartografías o aplicaciones que expanden la experiencia sensorial.

Ciertamente, los centros de memoria oficiales en el país poseen una infraestructura ideal para la creación de espacios virtuales de la memoria. Uno de los casos más significativos es el del Museo Casa de la Memoria, en Medellín, el cual cuenta con 10 recorridos virtuales de sus salas de exposición, cada uno de estos recorridos contiene componentes multimedia que emulan y aumentan la experiencia del visitante (Museo Casa de la Memoria, 2020). De forma similar, la propuesta del Museo Nacional de la Memoria Histórica (que se encuentra en proceso de construcción) provee salas virtuales de exhibición, abiertas al diálogo entre visitantes. Por último, el Centro de Memoria Paz y Reconciliación en Bogotá, sale del espacio del navegador de internet, ya que promociona su aplicación para dispositivos móviles. Todas estas experiencias son, sin duda, un avance importante en la promoción de los lugares de la memoria, especialmente para visitantes que se encuentran físicamente lejos de los sitios. Sin embargo, el diseño, presentación y mantenimiento de estas herramientas virtuales aún no capturan el universo total de los lugares de memoria Colombia.

Así, es importante señalar dos retos de los lugares de memoria y su trabajo dentro del espacio virtual. Como se ha discutido, los sitios físicos (que en ocasiones son en sí espacios representacionales de la memoria) tienen una fuerte carga emocional que permiten cuestionar, explicar y reflexionar sobre la narrativa presente. Una de las dificultades de la virtualidad yace, precisamente, en transmitir esa disposición para interpelar emocionalmente cuando se accede a las exhibiciones desde un sitio diferente al lugar de memoria. Los problemas de conexión y defectos en el sistema pueden afectar la experiencia, incluso la disposición de la persona visitante para participar en la invitación del recorrido (Bezerra et al., 2016). Un segundo reto tiene 
que ver con visitantes que no tienen acceso a la virtualidad. Ya de por sí, es problemático que algunos de los lugares de memoria no tengan acceso a tecnologías de información que les permita crear y transferir experiencias virtuales de los sitios en los que se desarrolla su trabajo de memoria personal, familiar y colectiva.

A pesar de estos retos, el trabajo de los lugares de memoria y sus diferentes objetivos es una práctica que requiere una constante reevaluación de sus lenguajes, tanto para su transmisión como para el cumplimiento de su intención reparadora. En este sentido, la mediación de la memoria a través de las tecnologías digitales significa la creación de nuevos contextos y formas de producción y consumo de la memoria (Apel, 2020). Aunque la investigación acerca de los procesos virtuales de los lugares de la memoria se encuentra en desarrollo, es importante resaltar el potencial de la experiencia virtual de la memoria en la producción de responsabilidad social y empatía. Landsberg (2004) introduce el concepto de memoria prostética para referirse a aquellas memorias que se derivan del encuentro entre persona y representaciones mediadas (tales como las visitas virtuales). Para Landsberg (2004), estas memorias se convierten en una prótesis que acompañan a visitantes en la construcción mediada de un trauma general. En este sentido, la ambición principal de la virtualidad de los lugares de memoria es mostrar su capacidad de extender no solo la experiencia individual en la construcción de memorias, sino también de presentarse como una alternativa pedagógica (Landsberg, 2004), en especial porque permite generar una disposición comunicativa que interpela a los y las visitantes, para provocar en estas personas el acontecimiento ético de hacerse cargo de la memoria y del pasado reciente como catalizador político del presente y del futuro.

\section{Lugares de memoria, territorio y comunidad. Una mirada al Museo Casa de la Memoria de MedelLín}

El Museo Casa de la Memoria nace con la necesidad de mostrar, a quienes no saben o son indiferentes la realidad del conflicto armado colombiano, cuáles son los daños que ha causado en los cuerpos, en los territorios y en las memorias de las personas que han sido víctimas. Para ello plantea diferentes acciones, procesos y escenarios de diálogo que construyen y reconstruyen las memorias, al proponer experiencias e intercambios con sus protagonistas. En este proceso son varias las experiencias significativas que podrían compartir, pero para el presente artículo se tomarán tres relevantes: la mediación, Expedición Maestro y Vacaciones Memorables.

La mediación, tanto en la presencialidad como en la virtualidad, se encuentra a cargo del estudiantado de diferentes disciplinas de las ciencias sociales, líderes y lideresas que día a día acompañan a las personas visitantes por las salas. Los recorridos abarcan diez exposiciones temporales que se encuentran a libre disposición en la página web, al igual que tres talleres temáticos recomendados para niñas y niños, donde se construye y conversa alrededor de tres temas importantes para el museo: la memoria, la reconciliación y la construcción de paz.

Por su parte, la Expedición Maestro es un proceso de reflexión y reivindicación de las memorias de las víctimas del conflicto armado. Se basa en el rol del profesorado como vocero y replicador de estas memorias; se expande el museo a las aulas de clase. El reto es que la discusión sobre la memoria sea transversal al currículo. Así, se logra con docente y víctimas la construcción de los relatos del territorio, y se identifica cómo ha afectado y dañado el conflicto, pero también las múltiples formas que han creado para hacer memoria y resistencia. Expedición Maestro ha impactado cientos de docentes que, hoy en día, se han vuelto cómplices de los objetivos del Museo y que día a día continúan transmitiendo a sus estudiantes lo construido en este proceso. Estas expediciones han permitido reflexionar sobre cuál ha sido el papel de la escuela, de las maestras y maestros en los momentos más álgidos del conflicto armado de Colombia, conocer sus relatos y cómo se han convertido estas personas y las escuelas en lugares de protección y resistencia para muchas poblaciones y territorios, pero sobre todo para muchas niñas, niños y adolescentes, que han quedado entre el fuego cruzado de los diferentes actantes armados, legales e ilegales. 
Por otro lado, Vacaciones Memorables es una propuesta para niñas, niños y adolescentes, donde las vacaciones y los recesos escolares se han convertido en oportunidades para el encuentro con diferentes lenguajes que les permitan reflexionar desde sus propias experiencias, reconocer cuáles han sido las causas y los impactos de del conflicto armado en los cuerpos, los territorios y las memorias de las personas. En este proceso se han visitado diferentes territorios de la ciudad de Medellín, como la comuna 9 Buenos Aires, la comuna 10 La Candelaria, la comuna 13 San Javier y la comuna 8 Villa Hermosa.

Este proceso se convierte en memorable porque durante varios días de caminatas por los diferentes territorios es posible conocer inicialmente el Museo Casa de la Memoria, caminar el centro de la ciudad y visitar algunos lugares de memoria como el Parque del Periodista, que alberga la escultura en memoria de las niñas y niños masacrados en el barrio Villatina en 1992 por agentes de la policía; el parque de San Antonio, donde está la escultura el Pájaro de Fernando Botero, que, en realidad, son dos: una de ellas es el reemplazo de la primera versión, la cual fue un punto de detonación de una carga explosiva en medio de un bazar con cientos de personas en 1995 y que el maestro se negó a reemplazar si se retiraban los restos de la anterior.

Además, en articulación con los colectivos de los territorios, se hace recorrido por la comuna 8 de la mano de dos líderes del territorio en el sector el Faro, lugar de asentamiento de cientos de familias víctima del desplazamiento forzado y que, como forma de resistencia, se han organizado como comunidad para exigir el acceso a derechos tan básicos como el agua potable, la vivienda e, incluso, el derecho a que se les reconozca como barrio por la administración municipal.

Las vacaciones memorables terminan con el colectivo Son Batá, por el Afrotour en la comuna 13, en el sector de las independencias, lugar donde sus habitantes, a partir de la memoria como denuncia y resistencia, se han negado a olvidar lo que ha pasado y se han encargado de que el resto tampoco se olvide de qué pasó en su territorio. Finalmente, es importante señalar que, para el Museo Casa de la Memoria, las experiencias son el resultado de la construcción conjunta con las personas y los territorios.

\section{Conclusiones}

Los lugares de memoria no sedimentan la memoria, puesto que están abiertos a la disputa propia de la construcción de memoria. Esta apertura de la memoria permite la construcción de significados sobre lo ocurrido en casos de conflicto armado, lo que da lugar a la semiosis nemotécnica, que puede ser entendida como una producción de sentido y significado que orienta la construcción de memoria efectuada por quien visita un lugar de memoria.

En esa línea, los lugares de memoria son básicamente lugares de enunciación; sin embargo, la interpretación que brinda un lugar de memoria no se puede programar, toda vez que estos lugares presentan una contingencia comunicativa. Esto es notorio tanto en la visita presencial como no presencial, ya que la experiencia subjetiva genera la posibilidad de varias significaciones para una misma pieza expuesta.

La fuerza formativa de los lugares de memoria radica en que permiten al sujeto acoger a la otredad, a la víctima. Este proceso tiene alta incidencia en los relatos que se ofrezcan sobre el pasado, ya que una memoria que se construya con la empatía podrá generar parámetros éticos para responsabilizarse de la construcción comunitaria de la paz. Dicha fuerza formativa se extiende a las posibilidades que brindan las propuestas virtuales que han incorporado algunos lugares y museos de la memoria, toda vez que pueden generar una interpelación que desencadene un acontecimiento ético para hacer a las personas visitantes responsables del pasado a partir de acciones del presente que garanticen una no repetición en el futuro.

En síntesis, se puede concluir que los lugares de memoria tienen un vínculo inmanente al patrimonio, sobre todo porque constituyen un legado potencial para las nuevas generaciones, toda vez que brindan elementos para coadyuvar en la no repetición de los hechos abyectos del conflicto. 
En efecto, se puede argumentar que la dimensión pedagógica de los lugares de memoria está intrínsecamente vinculada a la semiosis nemotécnica, ya que posibilita el acontecimiento ético de hacerse responsable de las víctimas ausentes del conflicto.

Finalmente, esta semiosis nemotécnica no queda recluida al espacio físico, sino que se puede extender a las plataformas virtuales, sin embargo, sigue siendo un campo abierto a la reflexión y el diseño, que podría ser objeto de nuevas investigaciones. De hecho, se recomienda seguir investigando la posibilidad pedagógica que tienen los lugares de memoria en su extensión virtual.

\section{ReFERENCIAS}

Allier, E. (2008). Los Lieux de mémoire: una propuesta historiográfica para el análisis de la memoria. Historia y Grafía, 31, 165-192. https://www.redalyc.org/pdf/589/58922941007.pdf

Apel, D. (2020). Calling memory into place. Rutgers University Press.

Belk, R. (2014). Digital consumption and the extended self.Journal of Marketing Management, 30(11-12), 1101-1118. http://dx.doi.org/10.1080/0267257X.2014.939217

Bezerra, D., Oliveria, P. y Serres, J. (2016). Cibermuseus e memória na rede: o Museu das Coisas Banais (MCB) como meio e lugar de memória. Museología e Patrimônio, 9(2), 137-159. http://revistamuseologiaepatrimonio.mast. br/index.php/ppgpmus/article/view/510 .

Birle, P., Carnovale, V., Gryglewski, E. y Schindel, E. (2010). Memorias urbanas en diálogo: Berlín y Buenos Aires. Editorial Buenos Libros-Fundación Henrich Böll Cono Sur.

Carreras, C. y Mancini, F. (2014). A story of great expectations: Past and present of online/virtual exhibitions. DESIDOC Journal of Library \& Information Technology, 34(2), 87-96. https://publications.drdo.gov.in/ojs/in dex.php/djlit/article/view/6749

Droguett, R. F., González, L. L. y Shafir, I. P. (2018). Recordar la dictadura chilena visitando lugares de memoria. Psicologia \& Sociedade, 30, 1-10. http://dx.doi.org/10.1590/1807-0310/2018v30179978

Cuesta, O. (2018). La formación de investigadores sociales desde marcos crítico-hermenéuticos: un análisis a la propuesta del Instituto Pensamiento y Cultura en América Latina-IPECAL. Revista Kavilando, 10(2), 356-374. https://www.kavilando.org/revista/index.php/kavilando/article/view/213

Congreso de la República de Colombia. (2011, 10 de junio). Ley 1448 de 2011. Diario Oficial, No. 48.096.

Ejército Zapatista de Liberación Nacional [EZLN]. (2003). Documentos y comunicados N. 4. Ediciones Era

Farman, J. (2012). Mobile interface theory. Routledge.

Fontal, O. (2013). Estirando hasta dar la vuelta al concepto de patrimonio. En O. Fontal-Merillas (Coord.), La educación patrimonial. Del patrimonio a las personas (pp. 10-22). Trea.

Jelin, E. (2002). Los trabajos de la memoria. Siglo XXI Editores.

Landsberg, A. (2004). Prosthetic memory. The transformation of American remembrance in the age of mass culture. Columbia University Press.

Mèlich, J. (2001). La ausencia del testimonio: ética y pedagogía en los relatos del Holocausto. Anthropos. Universidad Autónoma de Nuevo León

Montenegro, M., Piper, I., Fernández, R. y Sepúlveda, M. (2015). Experiencia y materialidad en lugares de memoria colectiva en Chile. Universitas Psychologica, 14(5), 1723-1734. https://dialnet.unirioja.es/servlet/articulo?codi $\mathrm{go}=5716440$

Mora, Y. (2013). Lugares de memoria: entre la tensión, la participación y la reflexión. Panorama, 7(13), 97-109. htt ps://dialnet.unirioja.es/descarga/articulo/4780112.pdf

Museo Casa de la Memoria. (2020). Recorridos virtuales. https://www.museocasadelamemoria.gov.co/recorridos-vir tuales/

Nora, P. (2001). Entre mémoire et histoire. En N. Pierre (ed.). Les lieux de mémoire (pp. 23-43). Gallimard. 
Nora, P. (2009). Les Lieux de Mémoire. LOM.

Piper, I., Fernández, R. y Iñiguez, L. (2013). Psicología social de la memoria: espacios y políticas del recuerdo. Psykhe, 22(2), 19-31. http://dx.doi.org/10.7764/psykhe.22.2.574

Ruiz-Tagle, D. y Toledo, M. (2009). Del uso pedagógico de lugares de memoria: visita de estudiantes de educación media al parque por la paz Villa Grimaldi (Santiago, Chile). Estudios pedagógicos (Valdivia), 35(1), 199-220. h ttps://scielo.conicyt.cl/pdf/estped/v35n1/art12.pdf

Sierra, Y. (2017). El litigio estético como categoría museológica. En J. Rubio Navarro y P. Vignolo (Ed.), Cátedra Anual de Historia Ernesto Restrepo Tirado. Museos Memoria Historia, 20 y 21 de octubre de 2016. (pp. 70-80). Universidad Externado de Colombia.

Silver, D. (1997). Review: interfacing American culture: The perils and potentials of virtual exhibitions. American Quarterly, 49(4), 825-850. https://www.jstor.org/stable/30041813

Sistema Nacional de Atención y Reparación Integral a las Víctimas [SNARIV]. (2015). Guía de lineamientos sobre la creación y apropiación social de lugares de memoria. Gobierno de Colombia.

Vicente, M. M. (2019). Una mirada al futuro próximo en la transformación de los cementerios desde la perspectiva de la Arquitectura Emocional. Revista Murciana de Antropologia, (26), 95-110. https://revistas.um.es/rmDoiu /article/view/380981

\section{Notas}

[1] El ensayo fue construido como una articulación de abordajes conceptuales basados en lecturas sobre los temas que se abordan en el texto. Las ideas y argumentos que se hilvanan a lo largo del artículo también dan cuenta de la experiencia e intereses individuales de cada persona autora. De allí que el uso que se le hace a la teoría esté centrado en articular concepciones que permitan nuevas síntesis que sirvan de nuevos postulados teóricos. La última parte recupera una experiencia puntual que sirve como referente concreto para hacer operativos los análisis que busca exponer el ensayo.

\section{INFORMACIÓN ADICIONAL}

Cómo citar: Cuesta Moreno, O. J., Lara Salcedo, L. M., Mora Hernández, Y., Burgos Urán, F. A., Sánchez Guerra, L. y Marín, A. M. (2022). Dimensión pedagógica de los lugares de memoria: semiosis nemotécnica, visita presencial y extensión virtual. Revista Educación, 46(1). http://doi.org/10.15517/revedu.v46i1.44708 